\title{
Caryocar brasiliense do Cerrado brasileiro ao tratamento de feridas - Revisão
}

\section{integrativa}

\author{
Brazilian Caryocar from the brazilian Cerrado to wound treatment - Integrative review \\ Caryocar brasileño del Cerrado brasileño al tratamiento de heridas - Revisión integrativa
}

Recebido: 22/05/2021 | Revisado: 28/05/2021 | Aceito: 29/05/2021 | Publicado: 01/06/2021

Tácio Fragoso Pereira

ORCID: https://orcid.org/0000-0002-7836-0925 Universidade Federal da Paraíba, Brasil E-mail: taciofragoso29@gmail.com

Maura Vieira dos Santos Sousa

ORCID: https://orcid.org/0000-0002-3540-502X Universidade Federal da Paraíba, Brasil E-mail: mauralabbiomat@gmail.com

Itamara Farias Leite

ORCID: https://orcid.org/0000-0002-9158-8609 Universidade Federal da Paraíba, Brasil

E-mail: itamaraf@gmail.com

\begin{abstract}
Resumo
Diariamente inúmeras pessoas no Brasil e no mundo são acometidas com lesões teciduais causadas por diversos fatores que podem gerar significativas perdas na pele. O próprio organismo após uma injúria tecidual começa o processo de reparação, porém quando realizado sem intervenção farmacêutica, o processo é demorado e muitas vezes essa cicatrização não é eficiente e deixa sequelas. Visando contornar esse problema, uma alternativa promissora para este fim, tem sido o uso do pequi, fruta típica do cerrado brasileiro, rico em ácidos graxos insaturados que vem sendo usado na medicina popular por seus efeitos anti-inflamatórios e cicatrizantes no tratamento de várias enfermidades assim como na reabilitação de lesões teciduais e, por esse motivo são alvos de pesquisas mais detalhada nesse trabalho. Este artigo trata-se de uma revisão integrativa sobre as potencialidades do pequi no tratamento de feridas, tendo o privilégio de unir duas áreas cientificas que é a grande biodiversidade brasileira e a saúde sobre uma abordagem interdisciplinar. Para a coleta dos dados, fez-se um levantamento bibliográfico no período de 2014 a 2021 e de 2009 a 2021 para periódicos de revisão e de pesquisa, respectivamente. As buscas foram realizadas, usando as bases de dados eletrônicos da BVS e indexadas como LILACS, SCIELO, PubMed, Google acadêmico e Science direct. Baseado nesse levantamento bibliográfico, pode-se comprovar o espectro de ação biológica do pequi quando utilizado no tratamento de feridas, apresentando resultados positivos no reparo e cicatrização tecidual, confirmados por meio de exames macroscópicos, histológicos e clínicos.
\end{abstract}

Palavras-chave: Caryocar brasiliense; Propriedades; Cicatrização tecidual.

\begin{abstract}
Every day countless people in Brazil and in the world are affected with tissue injuries caused by several factors that can generate significant skin losses. The body itself after a tissue injury begins the repair process, but when performed without pharmaceutical intervention, the process takes time and often this healing is not efficient and leaves sequelae. Aiming to circumvent this problem, a promising alternative for this purpose has been the use of pequi, a fruit typical of the Brazilian cerrado, rich in unsaturated fatty acids that has been used in folk medicine for its anti-inflammatory and healing effects in the treatment of various diseases. as well as in the rehabilitation of tissue injuries and, for this reason, they are targets of more detailed research in this work. This article is an integrative review on the potential of pequi in the treatment of wounds, having the privilege of uniting two scientific areas, which is the great Brazilian biodiversity and health under an interdisciplinary approach. For data collection, a bibliographic survey was carried out from 2014 to 2021 and from 2009 to 2021 for review and research journals, respectively. The searches were carried out, using the electronic databases of the VHL and indexed as LILACS, SCIELO, PubMed, Google academic and Science direct. Based on this bibliographic survey, it is possible to prove the spectrum of biological action of pequi when used in the treatment of wounds, presenting positive results in tissue repair and healing, confirmed through macroscopic, histological and clinical exams.
\end{abstract}

Keywords: Caryocar brasiliense; Properties; Tissue healing.

\section{Resumen}

Cada día innumerables personas en Brasil y en el mundo se ven afectadas por lesiones tisulares provocadas por varios factores que pueden generar importantes pérdidas de piel. El propio cuerpo después de una lesión tisular comienza el proceso de reparación, pero cuando se realiza sin intervención farmacéutica, el proceso lleva tiempo y, a menudo, esta 
curación no es eficiente y deja secuelas. Con el objetivo de sortear este problema, una alternativa prometedora para este propósito ha sido el uso del pequi, una fruta típica del cerrado brasileño, rica en ácidos grasos insaturados que se ha utilizado en la medicina popular por sus efectos antiinflamatorios y cicatrizantes en el tratamiento. de diversas enfermedades. así como en la rehabilitación de lesiones tisulares y, por ello, son objeto de investigaciones más detalladas en este trabajo. Este artículo es una revisión integradora sobre el potencial del pequi en el tratamiento de heridas, teniendo el privilégio de unir dos áreas científicas, que es la gran biodiversidad brasileña y la salud bajo un enfoque interdisciplinario. Para la recolección de datos se realizó un relevamiento bibliográfico de 2014 a 2021 y de 2009 a 2021 para revistas de revisión e investigación, respectivamente. Las búsquedas se realizaron, utilizando las bases de datos electrónicas de la BVS e indexadas como LILACS, SCIELO, PubMed, Google Academic y Science Direct. Con base en este relevamiento bibliográfico, es posible brindar el espectro de acción biológica del pequi cuando se utiliza en el tratamiento de heridas, presentando resultados positivos en la reparación y cicatrización de tejidos, confirmados mediante exámenes macroscópicos, histológicos y clínicos.

Palabras clave: Caryocar brasiliense; Propiedades; Curación de tejidos.

\section{Introdução}

O segundo maior bioma brasileiro é o cerrado, ocupando de acordo com o ministério do meio ambiente uma área de aproximadamente dois milhões de quilômetros quadrados, correspondendo a 23,92\% da área total do Brasil, localizado em diferentes estados brasileiros. Apresenta rica biodiversidade na fauna e flora; sua vegetação, formada grande parte por plantas herbáceas, arbustos e árvores de pequeno porte. O solo não é muito fértil, mas as plantas são capazes de sobreviver nesse ambiente (Francoso et al. 2015).

A flora no Cerrado é utilizada de forma sustentável como fonte de renda para a população local. Várias espécies se sobressaem em usos alimentícios, medicinais e artesanais. Tendo ainda muito o que se pesquisar para conhecer o potencial da flora do cerrado, buscando à valorização dos recursos existente (Santos, 2021).

O cerrado possui grande potencial de frutos e plantas com propriedades nutricionais e terapêuticas, que precisam ser mais estudados. Dentre eles, destaca-se o pequi (Caryocar brasiliense), fruta nativa do cerrado brasileiro, muito utilizada na culinária sertaneja, tendo grande relevância na parte econômica, cultural e saúde. O pequi é rico em proteínas, compostos bioativos e antioxidantes, usado na produção de fármacos. Muito utilizado na parte alimentícia, pois dele é extraído um óleo, chamado azeite de pequi, substituindo o tradicional óleo de cozinha (Batista et al. 2019).

O pequizeiro é uma árvore perene, podendo ser classificada como frutífera ou oleaginosa, por suas características e formas de se utilizar. Com várias utilidades, desde sua madeira até o fruto, podendo ser utilizado pelas indústrias de artesanato, culinária e farmacêutica. Apresenta também potencial de uso na fabricação de combustíveis e lubrificantes. As folhas contêm um extrato com atividade moluscicida e antifúngica testadas in vitro, frente à muitos microrganismos. O pequi ajuda também na cura ou diminuição de diversos problemas causados por várias doenças, como a gripe, bronquites, infecções broncopulmonar e inflamação. Segundo a farmacopeia popular as indústrias cosméticas por sua vez utilizam e se beneficiam das propriedades do óleo que possui uma excelente qualidade, partindo de sua polpa até a amêndoa (Lorenzi, 2017).

$\mathrm{Na}$ medicina popular, são construídas diversas possibilidades de tratamentos a partir de plantas, frutos, cascas de árvores e folhas sendo usados para tratamentos de resfriados, gripes, edemas. O óleo do fruto do pequi é usado para o tratamento de queimaduras e feridas em virtude de suas propriedades cicatrizantes (Garlet, 2019).

A busca pelo conforto do paciente, vítima de trauma ou patologia tem gerado a procura por novas possibilidades para uma ligeira e eficiente cicatrização de lesões. Um dos maiores destaques nessa área, são os produtos naturais (Richter, 2016), especificamente o óleo de pequi (Bertolino, 2019).

O valor terapêutico do óleo de pequi vem sendo pesquisado em grande variedade de experimentos científicos que comprovam sua real eficácia em uso medicinal (Barros, 2017).

A grande presença de ácidos graxos insaturados no óleo de pequi sugere boa previsibilidade na utilização desse produto como alternativa terapêutica para cicatrização. Esses ácidos graxos insaturados favorecem a obtenção de um curativo 
úmido oleoso, servindo assim como barreira protetora contra microrganismos, evitando a desidratação tecidual, mantendo a temperatura corporal, diminuindo os traumatismos e principalmente como um grande mediador pró-inflamatório, realizando a produção de fatores de crescimento, promovendo a fibroplasia e neovascularização (Bertolino et al. 2019).

A caryocar brasiliense sob a forma de óleo é constituída majoritariamente por ácidos graxos mono e insaturados, e terpenóides e ésteres. Ó óleo, se mostra com várias atividades biológicas como anti-inflamatória, antioxidante, cicatrizante, antifúngica, antimicrobiana e redução de problemas cardiovasculares. Tendo em vista, o amplo espectro de propriedades medicinais, este óleo tem aplicação no tratamento de infecções brônquio respiratórias, cicatrização de lesões cutâneas e, ultimamente, tem se tornado um grande aliado entre os adeptos de malhação devido ajudar na recuperação muscular. A polpa do pequi tem em sua constituição $60 \%$ de óleos comestíveis e 17,10\% de fibras. Outras pesquisas concluíram que a polpa e a amêndoa do pequi são ricas em vitaminas A, do complexo B e vitamina C (Almeida, 2018).

Nesse contexto, a realização de pesquisas com o óleo de pequi pode contribuir para uma melhor exploração deste recurso natural, abrangendo ainda mais suas aplicações, bem como financiar novas e eficazes formulações farmacêuticas no combate a diversas injúrias teciduais, ajudando dessa forma os profissionais de saúde e, principalmente os pacientes com tratamentos acessíveis, naturais e de baixo custo. O objetivo do trabalho foi realizar uma revisão integrativa sobre as potencializadas do óleo de pequi no tratamento de feridas.

\section{Material e Métodos}

A presenta pesquisa se classifica como quantitativa e exploratória, uma vez que buscou aplicações do óleo do pequi no tratamento de feridas (Gerhardt \& Silveira, 2009). O levantamento bibliográfico foi realizado através de um estudo do tipo revisão integrativa, que tem como finalidade, sintetizar os resultados obtidos em pesquisas de um determinado assunto em questão, de forma sistemática abrangente e ordenada. Chamada de integrativa pois oferece informações mais abrangente sobre determinado assunto ou problema, facilitando também na obtenção de informações.

Utilizados como critérios de inclusão na referida pesquisa: dissertações, trabalho de conclusão de curso (TCC), artigos de revisão bibliográfica e ensaios clínicos, que tratavam do potencial do óleo de pequi com aditivos ou não, no tratamento de feridas, sendo o fator principal a ser considerado na investigação.

Primeiro os artigos foram avaliados por títulos e resumos, comparando sua adequação ao tema e critérios de inclusão citados acima. Os trabalhos escolhidos para inclusão na pesquisa foram lidos por completo, buscando evidências sobre o potencial do óleo de pequi no tratamento de feridas cutâneas.

O levantamento bibliográfico foi realizado no período de janeiro de 2021 a maio de 2021, usando periódicos de revisão assim como de pesquisas nos anos de 2014 a 2021 e 2009 a 2021, respectivamente, nas referidas bases de dados eletrônicas da BVS e indexadas como LILACS, SCIELO, PubMed, Google Acadêmico e Science Direct. Na busca dos periódicos foi utilizada os seguintes descritores em português e inglês: Caryocar brasiliense, propriedades, cicatrização tecidual, Caryocar brasiliense, properties, tissue healing, respectivamente.

\section{Resultados e Discussão}

A revisão foi desenvolvida após leitura de 70 artigos, considerando os critérios de inclusão já citados acima, sendo selecionados 20 artigos para citação na tabela abaixo.

No Quadro 1, encontra-se 20 estudos de pesquisas in vivo e in vitro, envolvendo o uso do óleo de pequi no tratamento de feridas. Sendo escolhida em todas as pesquisas a aplicação tópica. 
Quadro 1 - Apresenta a seleção dos 20 artigos, cuja pesquisa está reportada abaixo, mostrando, inclusive os resultados obtidos.

\begin{tabular}{|c|c|c|c|}
\hline AUTOR & TÍTULO DO TRABALHO & DADOS DA PESQUISA & RESULTADOS OBTIDOS \\
\hline OLIVEIRA et al. (2020) & $\begin{array}{l}\text { Avaliação macroscópica da cicatrizacãa de } \\
\text { feridas de pele tratadas com extrato da folha de } \\
\text { pequizeiro (Caryocar brasiliense). }\end{array}$ & $\begin{array}{l}\text { MATERIAIS: Foram utilizados seis coelhos da raça Nova Zelândia, pesando aproximadamente } 2 \mathrm{~kg} \text {, com idade entre quatro e } \\
\text { seis meses, sendo três foram machos e três fêmeas. } \\
\text { MÉTODOS: Desenvolveu um extrato aquoso de folhas do pequizeiro para averiguar os seus efeitos na cicatrizaç̃õo em lesões } \\
\text { experimentalmente provocadas em coelhos. } \\
\text { AVALIAÇÃõ: Análise sobre o tempo de fechamento das lesões, presença ou não de edema, hiperemia e de exsudato, } \\
\text { averigundo o efeito anti-inflamatório do composto. }\end{array}$ & $\begin{array}{l}\text { O extrato aquoso da folha de pequi apresentou alteração na ocorrência } \\
\text { de hiperemia, fato que sugere a possibilidade de atividade anti- } \\
\text { inflamatória. }\end{array}$ \\
\hline COUTINHO et al. (2020) & $\begin{array}{l}\text { Pequi (Caryocar Brasiliense Cambess)-Loaded } \\
\text { Nanoemulsion, Orally Delivered, }\end{array}$ & $\begin{array}{l}\text { MATÉRIAIS: Utilizados ratos Wistar machos com } 5 \text { animais por gaiola. pesando aproximadamente de } 18 \text {-20g, aplicą̧ão } \\
\text { seguida por } 14 \text { dias em testes in vivo em lesões na parte de trás dos ratos. } \\
\text { MÉTODOS: foi produzido por nanoemulsões contendo óleo de pequi (pequi-NE) } \\
\text { AVALIAÇão: Analisadas por microscopia eletrônica de transmissão operando a } 120 \mathrm{Kv} \text {. }\end{array}$ & $\begin{array}{l}\text { O óleo nanoestruturado induziu a cicatrização dérmica in vivo de } \\
\text { forma eficaz quando comparada ao óleo livre. }\end{array}$ \\
\hline JUNIOR et al. (2020) & $\begin{array}{l}\text { Analgesic And Anti-Inflammatory Effects Of } \\
\text { Caryocar Brasiliense }\end{array}$ & $\begin{array}{l}\text { MATÉRIAIS: camundongos suíços } \\
\text { MÉTODOS: Doses de } 300,700 \text { e } 1000 \mathrm{mg} / \mathrm{kg} \text { de óleo de pequi foram administradas por via oral. } \\
\text { AVALIAÇÃO: Analisados três parâmetros de inflamação hiperalgesia mecânica, frio, hiperalgesia e edema, exames clínicos, } \\
\text { histológicos e biopsia. }\end{array}$ & $\begin{array}{l}\text { O edema da pata foi inibido com doses de } 700(\mathrm{P}<0,05) \text { e } 1.000 \mathrm{mgs} \\
\text { (P<0,001) de óleo de pequi após } 1,2 \text { e } 4 \text { horas após carrageenan. } \\
\text { Comprovando seu efeito anti-inflamatório. }\end{array}$ \\
\hline PIRES et al. (2020) & $\begin{array}{l}\text { Healing Of Dermal Wounds Property Of } \\
\text { Caryocar Brasiliense Oil Loaded Polymeric } \\
\text { Lipid-Core Nanocapsules: Formulation And In } \\
\text { Vivo Evaluation }\end{array}$ & $\begin{array}{l}\text { MATÉRIAIS: Ratos Wistar machos (peso médio } 120 \mathrm{~g} \text { ) } \\
\text { MÉTODOS: Hidrogel foi testado in vivo em lesões na parte de trás de ratos Wistar machos por } 14 \text { dias } \\
\text { AVALIAÇãO: Exames clínicos, histológicos e biopsias. }\end{array}$ & $\begin{array}{l}\text { O óleo nanoestruturado induziu a cicatrização dérmica in vivo mais } \\
\text { rápida quando comparada ao óleo livre. LNCCBC+ apresentaram } \\
\text { melhores resultados mostrando o maior aumento da produção de } \\
\text { colágeno tipo 1, uma proténa importante para o reparo tecidual. }\end{array}$ \\
\hline BEZERRA (2020) & $\begin{array}{l}\text { Avaliação pré-clínica do óleo de pequi } \\
\text { (Caryocar coriaceum Wittm.) e emuls̃a a base } \\
\text { deste para o tratamento da dermatite: } \\
\text { formulação, caracterização e efeitos } \\
\text { antimicrobiano e anti-inflamatório } \\
\end{array}$ & $\begin{array}{l}\text { MATÉRIAIS: camundongos (Swiss) fêmeas e pesando de } 25-30 \mathrm{~g} \text {, divididos em grupos de seis animais. } \\
\text { MÉTODOS: Emulsão O/A através do método de inversão de fases, tratamento tópico nos animais com o OFCC (ativo), vé́culo } \\
\text { (grupo controle) e dexametasona (anti-inflamatório). } \\
\text { AVALIAÇÃo: Avaliados em microscopia e macroscopia e biópsias. }\end{array}$ & $\begin{array}{l}\text { A emulsão apresentou efeito anti-inflamatório e acelerou a } \\
\text { cicatrização. }\end{array}$ \\
\hline MARTINS et al. (2019) & $\begin{array}{l}\text { Avaliação macroscópica da cicatrização de } \\
\text { lesões experimentalmente provocadas na pele de } \\
\text { coelhos e tratadas com pomada da folha do } \\
\text { pequizeiro (Caryocar brasiliense). }\end{array}$ & $\begin{array}{l}\text { MATERIAIS: Seis coelhos da raça Nova Zelândia, peso aproximado } 2 \text { kg, idade entre quatro e seis meses. } \\
\text { MÉTODOS: Divididos em dois grupos. Grupo I controle e Grupo II tratada pela solução do caryocar brasiliense. } \\
\text { A identificicąão das feridas foi denominada de acordo com a localização, cranial direita (CRD), cranial esquerda (CRE), caudal } \\
\text { direita (CAD) e caudal esquerda (CAE). } \\
\text { CRD e CAD tratada com água filtrada, CRE e CAE tratada com soluçãoo de caryocar. Aplicadas de forma tópica e padronizada. } \\
\text { AVALIAÇÃO: Análise macroscópica diária, verificando-se os seguintes parâmetros: edema, hiperemia e presença de exsudato e } \\
\text { estudo morfométrico no halo da ferida no dia da indução da ferida no } 7^{\circ} \text { e } 14^{\circ} \text { dia pós-induçăo }\end{array}$ & $\begin{array}{l}\text { Resultados significativos com o uso de óleo do pequi na redução de } \\
\text { cicatrizes cutâneas em ratos, que reduziu o tempo de fechamento de } \\
\text { lesão, e ainda promoveu uma menor mobilização de células } \\
\text { inflamatórias comparada ao grupo controle. }\end{array}$ \\
\hline ONOFRE (2019) & $\begin{array}{l}\text { Ação Do Óleo De Pequi (Caryocar Coriaceum) } \\
\text { No Processo De Cicatrização De Lesões } \\
\text { Cutâneas }\end{array}$ & $\begin{array}{l}\text { MATERIAIS: Foram divididos em dois grupos o controle denominado "C", e "T" os tratados com o óleo de pequi. O } \\
\text { experimento foi realizado em lesões cutâneas de ratos } \\
\text { MÉTODOS: No grupo tratado com óleo de pequi nos diferentes tempos experimentais foi observado maior percentual de } \\
\text { regressão das lesõos em relação ao grupo controle ( }<<0,05) \text {. } \\
\text { AVALIAÇÃO: Análise macroscópica e histopatológica do processo cicatricial até o } 14^{\circ} \text { dia de pós-operatório. }\end{array}$ & $\begin{array}{l}\text { A análise do processo de cicatrização sob os pontos de vista } \\
\text { macroscópico e histológico permitiu concluir que o uso do óleo de } \\
\text { pequi tem papel benéfico frente ao reparo tecidual. }\end{array}$ \\
\hline
\end{tabular}




\begin{tabular}{|c|c|c|c|}
\hline VASCONCELOS et al. (2017) & $\begin{array}{l}\text { Healing Action of Passion Fruit and Pequi } \\
\text { Creams on Induced Skin Lesions in Mice }\end{array}$ & $\begin{array}{l}\text { MATERIAIS: } 56 \text { camundongos adultos com peso de } 30 \mathrm{~g} \text { - } 40 \mathrm{~g} \text {. Divididos em } 4 \text { grupos, cada um com } 14 \text { camundongos. } \\
\text { MÉTODOS: Grupo I: Tratados com fibrinase. Grupo II: Tratados por Passiflora, creme de maracujá } 5 \% \text {. Grupo III Tratados } \\
\text { com óleo de pequi 10\%. Grupo IV: Tratados com solução salina 0,9\%. } \\
\text { AVALIAÇÃO: Análise morfométrica na área da ferida para verificação de cicatrização e análise histológica das lesões. Todas as } \\
\text { avaliaçōes e análises foram realizadas no } 7^{\circ} \text { e } 14^{\circ} \text { dia. }\end{array}$ & \\
\hline SILVA et al. (2016) & $\begin{array}{l}\text { Atividade anti-inflamatória do óleo de pequi } \\
\text { (caryocar coriaceum wittm) em sistema } \\
\text { microemulsionado. }\end{array}$ & 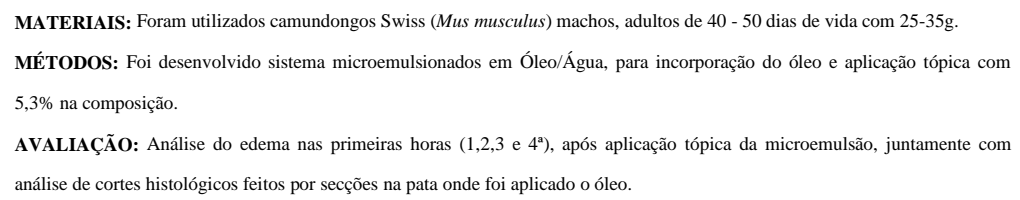 & $\begin{array}{l}\text { Microemulsão do óleo de pequi promoveu uma ótima atividade anti- } \\
\text { inflamatória (p<0,05), como redução do edema nas primeiras horas. }\end{array}$ \\
\hline RABBERS (2016) & $\begin{array}{l}\text { Desenvolvimento, caracterizaç̃ó e avaliação da } \\
\text { biocompatibilidade de compósito a base de } \\
\text { colágeno e óleo da polpa de pequi (caryocar } \\
\text { brasiliense camb). }\end{array}$ & $\begin{array}{l}\text { MATERIAIS: } 30 \text { ratos (Rattus novergicus albinus Wistar), machos, adultos, com aproxidamente } 90 \text { dias de vida. Biomaterial a } \\
\text { base de colágeno e óleo de pequi foi avaliado em comparação a membrana controle, constitúda de } 1,1 \% \text { colágeno e gelatina a } 1 \% \\
\text { sem adiçăo do óleo. } \\
\text { MÉTODOS: Formulação farmacêutica desenvolvida pela mistura da gelatina } 1 \% \text { e óleo de pequi em } 0,127 \text { g. Ao final se obteve } \\
\text { uma concentração de } 12,7 \% \text {. } \\
\text { AVALIAÇãO: Análises histopatológicas sendo retiradas nos seguintes dias: }\left(3^{\circ}, 77^{\circ}, 21^{\circ}, 28^{\circ} \text { e } 35^{\circ} \text { dia) comparando sempre sobre }\right. \\
\text { análises nas membranas controle. }\end{array}$ & $\begin{array}{l}\text { A presença do óleo de polpa de pequi reduziu a intensidade do } \\
\text { processo inflamatório e otimizou o recrutamento de fibroblastos e, } \\
\text { consequentemente, a produção de colágeno quando implantado em } \\
\text { subcutâneo de ratos. }\end{array}$ \\
\hline TORRES et al. (2016) & $\begin{array}{l}\text { Pequi (Caryocar brasiliense Camb.) almond oil } \\
\text { attenuates carbon tetrachloride-induced acute } \\
\text { hepatic injury in rats: Antioxidant and anti- } \\
\text { inflammatory effects }\end{array}$ & $\begin{array}{l}\text { MATÉRIAIS: } 40 \text { ratos Wistar machos foram utilizados, pesando entre } 120 \text { e } 180 \mathrm{~g} . \\
\text { MÉTODOS: tratados com óleo de amêndoa de pequi (PAO) (3 ou } 6 \mathrm{~mL} / \mathrm{kg} \text { ) por } 21 \text { dias. } \\
\text { AVALIAÇãO: Analisados por histopatológicos, perfil lipídico, peroxidação lipídica, desintoxicação e parâmetros inflamatớrios. }\end{array}$ & $\begin{array}{l}\text { O PAO aumentou a capacidade antioxidante aumentando as } \\
\text { atividades enzimáticas, bem como reduzindo as concentrações } \\
\text { circulantes de leptina e mediadores inflamatórios como interleucina- } 6 \text {, } \\
\text { leucotrienos }-4 \mathrm{e}-5 \mathrm{e} \text { o receptor do fator necrose tumoral. }\end{array}$ \\
\hline FIGUEIREDO et al. (2016) & $\begin{array}{l}\text { Caryocar Coriaceum Wittm. (Pequi) Fixed Oil } \\
\text { Presents Hypolipemic And Anti-Inflammatory } \\
\text { Effects In Vivo And In Vitro }\end{array}$ & $\begin{array}{l}\text { MATÉRIAIS: Ratos Wistar (Rattus norvegicus) } \\
\text { MÉTODOS: tratados com OFCC. Diferentes grupos de animais foram tratados com OFCC 500, } 1000 \text { e } 2000 \mathrm{mg} / \mathrm{kg} \text { e solução } \\
\text { salina a 0,9\% (p.o.) durante } 7,15 \text { e } 30 \text { dias. Ao final de cada período, os animais foram pesados e jejuados por } 12 \mathrm{~h} \text {, para posterior } \\
\text { coleta de sangue. } \\
\text { AVALIAÇão: Avaliado para os seguintes parâmetros bioquímicos: colesterol total, HDL C, LDL-C e triglicérides. }\end{array}$ & $\begin{array}{l}\text { Os resultados demonstraram que o óleo de correção de Caryocar } \\
\text { coriaceum apresenta atividade anti-inflamatória e, pela primeira vez, } \\
\text { descreve as açoes hipolipidêmicos, sobre efeito cardioprotetor. }\end{array}$ \\
\hline DINIZ (2015) & $\begin{array}{l}\text { Atividade anti-inflamatória de microemulsão } \\
\text { contendo óleo de pequi (Caryocar coriaceum } \\
\text { W.). }\end{array}$ & $\begin{array}{l}\text { MATERIAIS: Camundongos Adultos } 40 \text { - } 50 \text { dias de vida. Foram divididos em quatro grupos cada um com } 5 \text { animais. } \\
\text { MÉTODOS: Foram desenvolvidas microemulsões contendo } 5,3 \% \text { de óleo de pequi, } 47,1 \% \text { por fase aquosa, e } 47,6 \% \text { de } \\
\text { tensoativos. } \\
\text { AVALIAÇão: Avaliadas nas primeiras } 4 \text { horas de aplicação com intervalo de } 60 \text { minutos, análises em cortes histológicos no } \\
\text { local de estudo. }\end{array}$ & $\begin{array}{l}\text { Apresentou-se como promissor, com resultados positivos no } \\
\text { tratamento de feridas, melhorando a atividade anti-inflamatória. }\end{array}$ \\
\hline NASCIMENTO et al. (2015) & $\begin{array}{l}\text { Estudo da resistência cicatricial cutânea de ratos } \\
\text { tratados com óleo de pequi (Caryocar } \\
\text { brasiliense). }\end{array}$ & $\begin{array}{l}\text { MATERIAIS: } 40 \text { ratos Wistar (Rattus norvegicus), machos, com dez semanas de vida, pesando } 250 \text { a } 300 \mathrm{~g} \text {. } \\
\text { MÉTODOS: Divididos em dois grupos. Grupo I, denominado de controle com } 20 \text { ratos, tratamento placebo apenas com óleo } \\
\text { mineral. Dez animais estudado no período de sete dias, e dez para } 14 \text { dias. } \\
\text { Grupo II com } 20 \text { animais tratados com óleo de Caryocar brasiliense. Dez animais estudado no período de sete dias e dez para } 14 \\
\text { dias. } \\
\text { AVALIAÇãO: Realizado cortes de fragmentos longitudinal histológicos e picrosirius red para identificação. Após receber os } \\
\text { valores de percentuais de colágeno imaturo e maduro nas amostras, foi realizado o cálculo do índice de maturação do colágeno } \\
\text { (IMaC). }\end{array}$ & $\begin{array}{l}\text { O tratamento com o óleo da caryocar brasiliense melhorou a } \\
\text { cicatrizaçăo no tecido lesionado. As análises do estudo comprovaram } \\
\text { que houve uma aceleração no reparo da cicatrização. }\end{array}$ \\
\hline
\end{tabular}




\begin{tabular}{|c|c|c|c|}
\hline BEZERRA (2015) & $\begin{array}{l}\text { A ação do óleo de pequi (Caryocar brasiliense) } \\
\text { no processo cicatricial de lesões cutâneas em } \\
\text { ratos. }\end{array}$ & $\begin{array}{l}\text { MATERIAIS: } 20 \text { ratos, pesando aproximadamente } 300 \text { - 350g. divididos em dois grupos, Grupo I que é o controle e Grupo II } \\
\text { tratado com o óleo de pequi. Dividindo cada grupo em subgrupos, com } 5 \text { animais para cada. } \\
\text { MÉTODOS: Grupo controle não recebeu tratamento algum e Grupo II foram tratados por aplicação tópica díríia de } 1 \mathrm{ml} \text { do óleo } \\
\text { de pequi. } \\
\text { AVALIAÇãO: Análise na cicatrização da lesão pelo software Imagem J; por aspectos histológicos no } 7^{\circ} \text { e } 14^{\circ} \text { dia. }\end{array}$ & $\begin{array}{l}\text { Grupo II que houve a aplicação tópica do óleo de pequi, teve } \\
\text { regressão da lesão quando comparado ao Grupo controle, ocorrendo } \\
\text { também um menor número de células inflamatórias e maior número } \\
\text { de fibroblastos quando comparado ao grupo controle. }\end{array}$ \\
\hline COELHO et al. (2013) & $\begin{array}{l}\text { Cenostigma macrophyllum Tul. on the healing of } \\
\text { skin wounds in rats with Diabetes mellitus. }\end{array}$ & $\begin{array}{l}\text { MATÉRIAIS: Sessenta três ratos Wistar masculinos. } \\
\text { MÉTODOS: Lesão cirúrgica ( } 2,5 \mathrm{~cm} \text { de diâmetro) na parte de trás dos animais. Aplicação tópica do grupo da planta de emulsão } \\
\text { óleo em água ( } 0,5 \mathrm{ml}) \text {. } \\
\text { AVALIAÇÃO: Avaliadas por processamento histológico. }\end{array}$ & $\begin{array}{l}\text { Redução do percentual de células inflamatórias e aumento do número } \\
\text { de fibroblastos. } \\
\text { A emulsão óleo-em-água acelerou a cicatrizaç̃̃o de feridas em ratos } \\
\text { diabéticos. }\end{array}$ \\
\hline OLIVEIRA et al. (2010) & $\begin{array}{l}\text { In vivo topical anti-inflammatory and wound } \\
\text { healing activities of the fixed oil of Caryocar } \\
\text { coriaceum Wittm. seeds. J Ethnopharmacol. }\end{array}$ & $\begin{array}{l}\text { MATERIAIS: } 5 \text { camundongos divididos em } 9 \text { grupos, cada um com } 5 \text { animais. Aplicaç̃o em quinze ou uma hora após } \\
\text { realização da inflamação } \\
\text { MÉTODOS: Foram divididos em grupos o G1: xileno controle; G2 FOCC (óleo de Pequi); G3- G6 recebeu FOCC a 6\%, 12\%, } \\
\text { 25\% e } 50 \% \text { em Cloreto de sódio (NaCl) a 0,9\% e o G7 recebeu FOCC a 100\%, aplicado topicamente imediatamente após o } \\
\text { xileno; G8 e G9 receberam dexametasona ( } 2,5 \mathrm{mg} / \mathrm{kg} \text { ) e indometacina ( } 5 \mathrm{mg} / \mathrm{kg} \text { ) por via oral durante } 3 \text { dias. } \\
\text { AVALIAÇÃO: Analise do edema de acordo com o peso das orelhas em análises histológica. }\end{array}$ & $\begin{array}{l}\text { A presennça do óleo de pequi inibe a inflamação tópica e ajuda na } \\
\text { aceleração do reparo cutâneo. }\end{array}$ \\
\hline SARAIVA et al. (2010) & $\begin{array}{l}\text { Topical Anti-Inflammatory Effect Of Caryocar } \\
\text { Coriaceum Wittm. (Caryocaraceae) Fruit Pulp } \\
\text { Fixed Oil On Mice Ear Edema Induced By } \\
\text { Different Irritant Agents }\end{array}$ & $\begin{array}{l}\text { MATÉRIAIS: Camundongos sứços, machos e fêmeas (Mus musculus), pesando } 25-35 \mathrm{~g} \text {. } \\
\text { MÉTODOS: óleo fixo de polpa de frutas (CCFO) foi obtido a partir de frutas Caryocar coriaceum utilizando acetato etilico } \\
\text { como solvente, ácido aracidônico (AA), capsaicina, fenol e histamina para camundongos suíços foi usado para avaliar o efeito } \\
\text { anti-inflamatório tópico do CCFO. } \\
\text { AVALIAÇÃO: Análise histológica das orelhas dos camundongos. }\end{array}$ & $\begin{array}{l}\text { O CCFO apresentou um perfil semelhante de atividade anti- } \\
\text { inflamatória tópica à de drogas utilizadas na farmacologia para o } \\
\text { tratamento. O estudo também mostrou o potencial do CCFO como um } \\
\text { importante medicamento à base de plantas contra lesōes inflamatórias } \\
\text { cutâneas. }\end{array}$ \\
\hline QUIRINO et al. (2009) & $\begin{array}{l}\text { Atividade cicatrizante e gastroprotetora de } \\
\text { Caryocar Coriaceum Wittm. }\end{array}$ & $\begin{array}{l}\text { MATERIAIS: Os ratos foram divididos em dois grupos, (n=10), chamados de OCC e controle. } \\
\text { MÉTODOS: Foram utilizados ratos albinos (Rattus norvegicus), pesando } 150-300 \mathrm{~g} \text { camundongos albinos (Mus musculus), } \\
\text { pesando } 20 \text {-30g. } \\
\text { AVALIAÇãO: Análise macroscópica foi realizada a cada } 72 \text { horas pelos parâmetros de escolada PUSH e avaliação } \\
\text { histopatológica no } 16^{\circ} \text { dia pós-operatório }\end{array}$ & $\begin{array}{l}\text { Animais tratados com o óleo de pequi mostrou aumento significativo } \\
\text { da contração da ferida quando comparado ao grupo controle. } \\
\text { A análise fitoquúmica do óleo de Pequi revelou a presença de ácidos } \\
\text { graxos onde demonstraram a efićácia destes agentes na cicatrização. }\end{array}$ \\
\hline
\end{tabular}

Fonte: Autores. 
Na sociedade atual a utilização de plantas e seus derivados é uma prática comum como forma terapêutica, estando dentro dos aspectos da cultura popular. Buscar à natureza para amenizar sintomas ou curar enfermidades é uma prática utilizada à longas datas (Vieira 2018).

Voltar no tempo e lembrar sobre o uso de plantas e óleos medicinais é algo que nos norteia sobre a importância dos conhecimentos da sociedade nativa e das interações com o meio ambiente que geram grandes benefícios para sociedade de uma forma geral, nos dias atuais quanto futuramente. Não esquecendo sobre a necessidade de investigar as riquezas da biodiversidade e principalmente da flora medicinal, fazendo uso desses meios de forma racional (Beleza 2016).

Os óleos essenciais são compostos orgânicos, extraídos de plantas ou frutos com uma grande composição química. São óleos utilizados desde a antiguidade com finalidades medicinais e estéticas, tendo seu uso até os dias atuais; grandes aliados das indústrias farmacêuticas, alimentos, perfumaria e cosmética (Branquinho 2015).

Essa facilidade em seu uso por diversas áreas se dá pelo amplo espectro de propriedades terapêuticas existentes (Mori et al. 2016).

Segundo Nascimento (2018) o óleo da polpa e amêndoa do pequi por possuírem em sua composição ácidos graxos, mostra que grande parte é formada por ácido oleico (53,9\%) e ácido palmítico (40,2\%). Segundo Araújo (2016), essa composição lhes dá características únicas e valiosas de cristalização e derretimento, que são essenciais sobre o desenvolvimento de determinados produtos, tendo como temperatura de fusão a mesma do corpo humano $\left(37^{\circ} \mathrm{C}\right)$.

Emerenciano et al. (2016), realizaram um estudo analítico onde comprovaram que o óleo de pequi além de apresentar em sua composição química vários ácidos graxos, com destaque ao oleico e palmítico, existem também na composição ácidos graxos esteárico, mirístico, linoléico e linolênico, conferindo propriedades muito importantes no processo de reparação tecidual.

Segundo Serra et al. (2020), Pesquisas mostram e comprovam o uso dos ácidos graxos no tratamento de feridas em aplicação tópica, que são fundamentais para recuperação e manutenção de barreiras cutâneas. Tanto a semente quanto o óleo da polpa do pequi são utilizados como mediadores no processo de cicatrização tecidual.

O processo de cicatrização tecidual é separado por fases, uma delas é a hemostasia; fase inflamatória, tem a formação do tecido de granulação e deposição da matriz extracelular; fibras reticulares, colágeno e elastina. Outra fase é a remodelação, sendo a última fase na cicatrização. Realizada no colágeno e matriz com duração de meses. Sendo responsável no aumento da força de tensão e diminuição no tamanho da cicatriz e eritema da lesão (martelli 2016).

Todos os trabalhos aqui reportados, mostraram o potencial do pequi no reparo e cicatrização tecidual sob diversas formas farmacêuticas de aplicação tópica: óleo, pomadas da folha, extrato da casca, emulsões e outros. Todos eles comprovam a ação biológica e cicatrizante no tratamento de feridas, fazendo uso de recursos naturais e sustentáveis para o desenvolvimento de formulações farmacêuticas promissoras para área de saúde.

\section{Considerações Finais}

A partir desse estudo pode-se elencar as propriedades medicinais da fruta pequi, típica do cerrado brasileiro, além de ser muito utilizada na culinária sertaneja. A extração de suas polpas e sementes dá origem a um óleo com amplo espectro de propriedades biológicas com potencial de aplicação no tratamento de lesões cutâneas que acometem inúmeras pessoas no país e no mundo como reportados no quadro acima.

Atualmente, existem poucas pesquisas que comprovem os mecanismos bioquímicos e fisiológicos desse óleo e sua ação cicatrizante, como também o potencial tóxico desses componentes, sendo importante comprovações cientificas para certificar e validar seu uso nas variadas enfermidades. 
Através desse levantamento bibliográfico, foi possível observar que não existem estudos sobre os efeitos adversos e reações de citotoxicidade que podem ocorrer na utilização do óleo em determinadas concentrações sobre certas ações terapêuticas, especialmente, cicatrização de feridas cutâneas.

Todos os artigos de pesquisa encontrados foram realizados sobre testes in vitro e in vivo, com diferentes concentrações e formas do óleo e aditivos.

\section{Referências}

Almeida, A. S. M, E., Silva, D. C. G., Farias, E. \& Santos, C. R.O. (2018). Óleo de pequi (Caryocar brasiliense Camb) métodos de extração, constituição química e propriedades medicinais. Diversitas Journal, 3(3), 557-563. https://doi.org/10.17648/diversitas-journal-v3i3.581

Araújo, A.C.M.A. (2016). Obtenção do óleo de sementes dos frutos do cerrado pequi (Caryocar brasiliense Camb) e murici (Byrsonima crassifolia) utilizando diferentes solventes no processo de extração / Ana Cristina Moreira Andrade Araújo. - Lavras: UFLA.

Barros, D.B. (2017). de Síntese e caracterização de estruturas nanotubulares de dióxido de titânio funcionalizadas com emulsões de líquido iônico e óleo fixo de pequi (Caryocar coriaceum Wittm) e avaliação da citotoxicidade sobre osteoblastos / Daniela Bomfim de Barros.

Batista, F.O. \& Sousa, R.S. (2019). Compostos bioativos em frutos pequi (Caryocar brasiliense camb.) e baru (Dipteryx alata vogel) e seus usos potenciais: uma revisão. Brazilian Journal of Development, 5(7), 9259-70, jul. (B2)

Batista, J. S. (2010). Avaliação da atividade cicatrizante do óleo de pequi (caryocar coriaceum wittm) em feridas cutâneas produzidas experimentalmente em ratos. Arq. Inst. Biol., São Paulo, 77(3), .441-447, jul./set.

Beleza, J.A.M. (2016). Plantas medicinais e fitoterápicos na atenção primária à saúde: contribuição para profissionais prescritores / Jussara Alice Macedo Beleza. - Rio de Janeiro.

Bertolino, J. F., Ferreira, K., Mascarenhas, L.J., Oliveira, L.P., \& Vulcani, V. (2019). Aplicabilidade do óleo de pequi na cicatrização. Enciclopédia Biosfera, 16(29).

Bezerra, N. K. M. S., Barros, T.L. \& Coelho, N.P.M.F. (2015). A ação do óleo de pequi (Caryocar brasiliense) no processo cicatricial de lesões cutâneas em ratos. Rev. bras. plantas med., Botucatu, 17(4), supl. 2, 875-880.

Bezerra, R. G. (2020). Avaliação pré-clínica do óleo de pequi (Caryocar coriaceum Wittm.) e emulsão a base deste para o tratamento da dermatite: formulação, caracterização e efeitos antimicrobiano e anti-inflamatório. 2020. 107 f. Dissertação (Mestrado em Ciências Farmacêuticas) - Faculdade de Farmácia, Odontologia e Enfermagem, Universidade Federal do Ceará, Fortaleza.

Branquinho, N.A.D.A. (2015). Avaliação de teor e composição química dos óleos essenciais de três espécies de Hyptis, submetidas a diferentes velocidades e temperaturas de secagem. / Núbia Angélica de Ávila Branquinho. Rio Verde.

Coelho, N.P.M.D. (2013). Cenostigma macrophyllum Tul. on the healing of skin wounds in rats with Diabetes mellitus. Acta Cir. Bras. [online], vol.28, n.8 [cited 2021-04-07], pp.594-600. ISSN 1678-2674. https://doi.org/10.1590/S0102-86502013000800007.

De Sá Coutinho, D., Pires, J., Gomes, H., Raffin, P.A., Satanisçuaski, G.S., Rodrigues, S.P.M., Martins, M.A., Ferrarini, S.R. \& Bernardi. (2020). A. Pequi (Caryocar brasiliense Cambess)-Loaded Nanoemulsion, Orally Delivered, Modulates Inflammation in LPS-Induced Acute Lung Injury in Mice. Pharmaceutics. 2020 Nov 11;12(11):1075. doi: 10.3390/pharmaceutics12111075. PMID: 33187057; PMCID: PMC7696187.

Diniz, D. M. (2015). Atividade anti-inflamatória de microemulsão contendo óleo de pequi (Caryocar coriaceum W.). 2015. 37f. Trabalho de Conclusão de Curso (Graduação em Farmácia) - Universidade Estadual da Paraíba, Campina Grande.

Emerenciano, N.M.J. (2016). Avaliação da atividade antibacteriana do óleo de Pequi extraído artesanalmente (Caryocar sp.) / Nathália Moura Jordão Emerenciano. - Vitória de Santo Antão.

Figueiredo, P.R.L., Oliveira, I.B., Neto, J.B.S., De oliveira, J.A., Ribeirol, D.B.V.G.S., Rocha, T.M., Rocha, T.M., Leal, L.K.A.M.., Kertopf, M.F., Felipe, C.F.B., Coutinho, H.D.M. \& De Alencar, M.I.R. (2016). Caryocar coriaceum Wittm. (Pequi) fixed oil presents hypolipemic and anti-inflammatory effects in vivo and in vitro. J Ethnopharmacol. 2016 Sep 15;191:87-94. doi: 10.1016/j.jep.2016.06.038. Epub 2016 Jun 15. PMID: 27321275.

Francoso, R., Brandão, R., Nogueira, C., Salmona, Y., Machado, R.B. \& Colli, G.R. (2015). Habitat loss and the effectiveness of protected areas in the Cerrado biodiversity hotspot. Natureza e conservação 13, 35- 40. 2015 doi: 10.1016/j.ncon.2015.04.001

Garlet, T.M.B. (2019). Plantas medicinais nativas de uso popular no Rio Grande do Sul [recurso eletrônico] / [Tanea Maria Bisognin Garlet]. - Santa Maria, RS: UFSM, PRE.

Gerhardt, T. E. \& Silveira, D. T. (2019). Métodos de Pesquisa. Coordenado pela Universidade Aberta do Brasil - UAB/UFRGS e SEAD/UFRGS. Porto Alegre: Editora da UFRGS.

Hatakana, E. \& Curi, R. (2007). Fatty acids and wound healing: a review. Revista Brasileira de Farmácia, 88(2).53-58, 2007.

Junior, A.J., Leitão, M.M., Bernal, L.TP.T., Kukaoka, O.A.M., Justi, P.A.E.J. \& Argandona, K.C. (2020). Analgesic and Anti-inflammatory Effects of Caryocar brasilienseMed Chem. 2020;19(3):313-322. doi: 10.2174/187152301866190408144320. 30961515. 
Lorenzi, R.A. (2017). Avaliação da estabilidade e potencial atividade antioxidante de óleo de pequi em emulsões cosméticas (Caryocar brasiliense Camb.) / Aléxia Lorenzi Raiser. - - 201750 f.: il. color.; $30 \mathrm{~cm}$.

Marques S.R. Peixote, C.A., Messias, J.B., Peixoto, C.A., Messias, J.B., Albuquerque, A.R. \& Silva, J.V.A. (2004). The effects of topical application ofsunflower- seed oil on open wound in lambs. Acta Cirúrgica Brasileira, 19(3), p.91103.

Martelli, A., Theodoro, V., Zaniboni, V.E., Freitas, B.A., Pastre, G.M., Melo, K.M., Andrade, T.A.M.. \& Santos, G.M.T. (2016). Microcorrente no processo de cicatrização: revisão da literatura. Archives of Health Investigation, 5(3).

Martins, D. L. (2019). Avaliação macroscópica da cicatrização de lesões experimentalmente provocadas na pele de coelhos e tratadas com pomada da folha do pequizeiro (Caryocar brasiliense). 23f. Trabalho de Conclusão de Curso (Graduação em Medicina Veterinária) - UniRV- Universidade de Rio Verde, Rio Verde.

Mori, H. (2016). Wound healing potential of lavender oil by acceleration of granulation and wound contraction through induction of TGF- in a rat model. Bmc Complementary And Alternative Medicine. 2016; 16 (1): 144

Nascimento, L.M. (2018). Óleo de pequi: um nutracêutico com propriedades antioxidantes: uma revisão de literatura. 2018. 54 f., il. Trabalho de Conclusão de Curso (Bacharelado em Farmácia) —Universidade de Brasília, Brasília.

Nascimento, M.W., Cleubianne, M.M.F., Antonio, L.S.D.C., Charllyton, L.M., Marcelino, S.D.A. \& Karine, A. (2015). Estudo da resistência cicatricial cutânea de ratos tratados com óleo de pequi (Caryocar brasiliense). ConScientiae Saúde [en linea]. 2015, 14(3), 449-455. ISSN: 1677-1028.

Nascimento, W.M. (2015). Estudo da resistência cicatricial cutânea de ratos tratados com óleo de pequi (Caryocar brasiliense). ConScientiae Saúde, vol. 14, núm. 3, 2015, pp. 449-455.

Oliveira, E.J., Martins, L.D., Dias, R.P.M. \& Treichel, E.L.T. (2020). Avaliação macroscópica da cicatrização de feridas de pele tratadas com extrato da folha de pequizeiro (Caryocar brasiliense). Braz. J. of Develop., Curitiba, 6(4), 17649-17659, apr.

Oliveira, M. L. (2010). In vivo topical anti-inflammatory and wound healing activities of the fixed oil of Caryocar coriaceum Wittm. seeds. J Ethnopharmacol. $129(2), 214-9$.

Onofre, A.S. (2019). Ação do Óleo de Pequi (Caryocar coriaceum) no processo de cicatrização de lesões cutâneas. In: VI Jornada Acadêmica de Farmácia Universidade de Brasília, 2019.

Pires, G.S.T., Sinhorin, V.D.G., Damazo, A.S., Bicudo, R.C., Cavalheiro, L., Valladão, P.A.R., Pohlmannar, A.R. \& Guterres, S. (2020). Healing of dermal wounds property of Caryocar brasiliense oil loaded polymeric lipid-core nanocapsules: formulation and in vivo evaluation Eur J Pharm Sci. 2020 Jul 1; 150:105356. doi: 10.1016/j.ejps.2020.105356.

Quirino, G.D.S. (2016). Q8a Atividade cicatrizante e gastroprotetora de Caryocar coriaceum Wittm. 118p.; il.

Rabbers, A.S. (2019). Efeito aditivo do óleo de pequi de polpa (Caryocar brasiliense Camb.) sobre a biocompatibilidade das membranas de colágeno e gelatina em implantes subcutâneos. O Arq. Sutiãs. Med. Zootec., Belo Horizonte 71(3), 811-818.

Raberrs, A. S. (2019). Desenvolvimento, caracterização e avaliação da biocompatibilidade de compósito a base de colágeno e óleo da polpa de pequi (caryocar brasiliense camb.) Dissertação (Mestrado em Ciência Animal) -Escola de Veterinária e Zootecnia, Universidade Federal de Goiás. Goiânia, $72 f$.

Richter, V.B. (2016). Evidence in practice of tissue healing with latex biomembrane: na integrative review. 2016. 70p. Publication n ${ }^{\circ}$. 056A/2016. Dissertation (Master degree) - Faculdade do Gama, Universidade de Brasília, Brasília/DF.

Rocha, J.A.M., Oliveira, R.G., Farias, R.E., Andrade, L.C.F. \& Aerestrup, F.M. (2006). Modulação da proliferação fibroblástica e da resposta inflamatória pela terapia a laser de baixa intensidade no processo de reparo tecidual. An. Bras. Dermatol. Rio de Janeiro, 81(2):150-156.

Sá Coutinho, D., Pires, J., Gomes, H., Raffin, P.A., Stanisçuaski, G.S., Rodrigues, S.P.M., Martins, M.A., Ferrarini, S.R. \& Bernardi, A. (2020). Pequi (Caryocar brasiliense Cambess)-Loaded Nanoemulsion, Orally Delivered, Modulates Inflammation in LPS-Induced Acute Lung Injury in Mice. Pharmaceutics 2020, 12, 1075. https://doi.org/10.3390/pharmaceutics12111075

Santos, V.S.DA. (2021). "Fauna e Flora do Cerrado"; Brasil Escola.

Saraiva, RA., Arauna, M.K., Oliveira, R.C., Menezes K.D., Leite, G.O., Kerntopf, M.R., Rocha, J.B., Tome, A.R., Campos, R.A. \& Menezes, I.R. (2010). Topical anti-inflammatory effect of Caryocar coriaceum Wittm. (Caryocaraceae) fruit pulp fixed oil on mice ear edema induced by different irritant agents. $\mathrm{J}$ Ethnopharmacol. 2011 Jul 14;136(3):504-10. doi: 10.1016/j.jep.2010.07.002. Epub 2010 Jul 17. PMID: 20621180.

Serra, D. S., Matias, D.S., Costa, D.S., Andrade, L.D.L., Gondim, F., Evangelista, D.A.D.S., Moura, D.O. \& Ávila Pimenta, A. T. (2020). Effects of fixed oil of Caryocar coriaceum Wittm. Seeds on the respiratory system of rats in a short-term secondhand-smoke exposure model. Journal of Ethnopharmacology. doi:10.1016/j.jep.2020.112633.

Silva, G.C.L. (2016). Atividade anti-inflamatória do óleo de pequi (caryocar coriaceum wittm) em sistema microemulsionado. Anais I CONBRACIS. Campina Grande: Realize Editora, 2016.

Torres, L. R. O., Santana, F. C.,Torres, F. L., Mello, I. L. P., Yoshime, L. T., Matos, E. M., Seelaender, M. C. L., Araujo, C. M. M., Cogliate, B. \& Mancinfilho. (2016). Pequi (Caryocar brasiliense Camb.) almond oil attenuates carbono tetrachlorideinduced acute hepatic injury in rats: Antioxidant and anti-inflammatory effects. Food and Chemical Toxicology, 97, 205-216.

Vasconcelos, E. A. (2017). Healing Action of Passion Fruit and Pequi Creams on Induced Skin Lesions in Mice. International Journal of Pharmaceutical Science Invention. 6 (7), 36-43.

Vieira, B. R. (2018). As plantas a farmácia e o sagrado: aspectos do uso popular e seu lugar na sociedade contemporânea. 96 f. Monografia (Graduação em Farmácia) - Escola de Farmácia, Universidade Federal de Ouro Preto, Ouro Preto. 